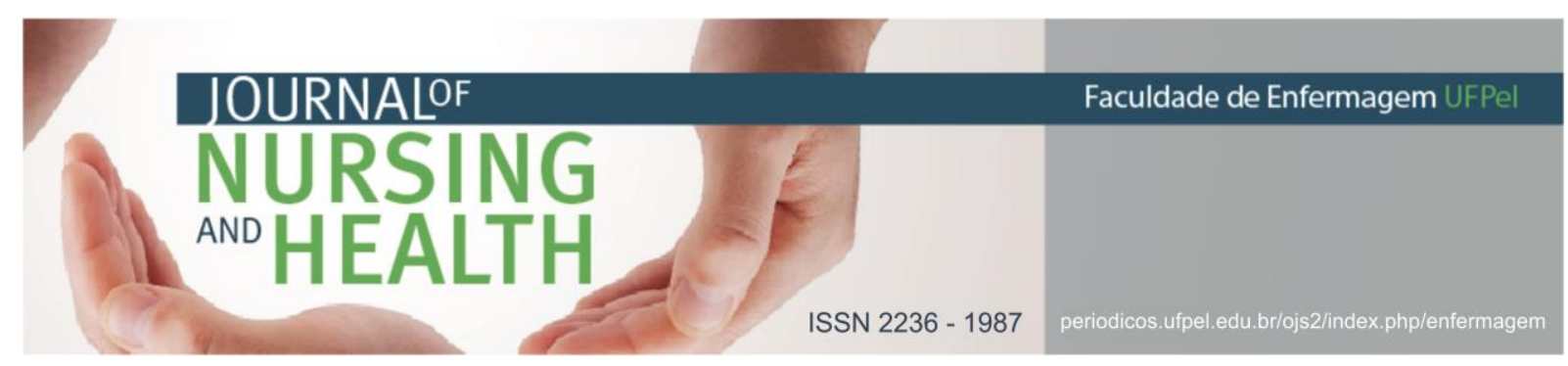

EDITORIAL

\title{
Qualidade do cuidado e segurança do paciente: uma reflexão
}

\author{
Quality of care and patient's safety: a reflection
}

\section{Cualidad de cuidado y seguridad del paciente: una reflexión}

Tahara, Ângela Tamiko Sato ${ }^{1}$

Passei alguns dias refletindo sobre o que seria importante falar da gestão da qualidade do cuidado e da segurança do paciente, porque entender ser esta temática polêmica e está sendo pauta de discussões em muitos países, haja vista os dados alarmantes sobre o número de erros e de eventos adversos publicados e subnotificados. Então, decidi refletir com vocês em outra perspectiva.

Vejo ao longo da minha experiência profissional uma busca constante de novos métodos, conceitos, modelos, técnicas e conhecimentos das ciências e das tecnologias inovadoras. Mesmo assim, ainda perdemos muitas vidas (pacientes e familiares) e causamos sofrimentos àquelas a quem prestamos cuidados nos serviços de saúde. Esse sofrer associa-se a constantes perdas de vidas, sobrecarga e condições inadequadas de trabalho e processos jurídicos decorrentes. Ao longo da minha história, não tenho visto soluções definitivas.

E agora, o que podemos fazer para superar esta situação tão drástica em nosso cotidiano? Como descobrir onde está a solução? É a questão concreta, a vivência de luta da maioria das nossas colegas durante toda a vida profissional! Para superá-la, programamos reuniões e eventos, preparamos nossos parceiros de trabalho, organizamos conferências, convidando os conferencistas, pesquisadores famosos que abordam a temática da qualidade e da segurança do paciente. Eles apontam cada vez mais sobre a importância da humanização e promovem os discursos sobre novas tecnologias, métodos e conceitos belíssimos... Mas, nada de resolver a questão! Por que será?

Por que não conseguimos superar essa situação, com tantos recursos e estratégias de ponta que temos e utilizamos? Nesse sentido, resolvi voltar às nossas origens, para que possamos repensar nessa situação e me lembrei de um pensamento do filósofo grego Sócrates (469-399 a.C) - estudioso que marcou uma reviravolta na história humana, deixando para nós muitos ensinamentos, em formas de frases significativas, e escolhi uma dessas que é: "Sábio é aquele que conhece os limites da própria ignorância". ${ }^{1}$

Interpretando a frase socratiana para a atual realidade, acredito que não adianta querer mudar e/ou melhorar qualquer situação da qualidade dos serviços ou da segurança das pessoas, se o prestador de serviço não reconhece suas próprias limitações de conhecimento e dos discernimentos. Se esta pessoa não tiver atitude

\footnotetext{
1 Enfermeira. Doutora em Ciências da Saúde. Professor Associado IV da Escola de Enfermagem da Universidade Federal da Bahia, Salvador, Bahia, Brasil. E-mail: angelatahra@hotmail.com; tahara@ufba.br
} 


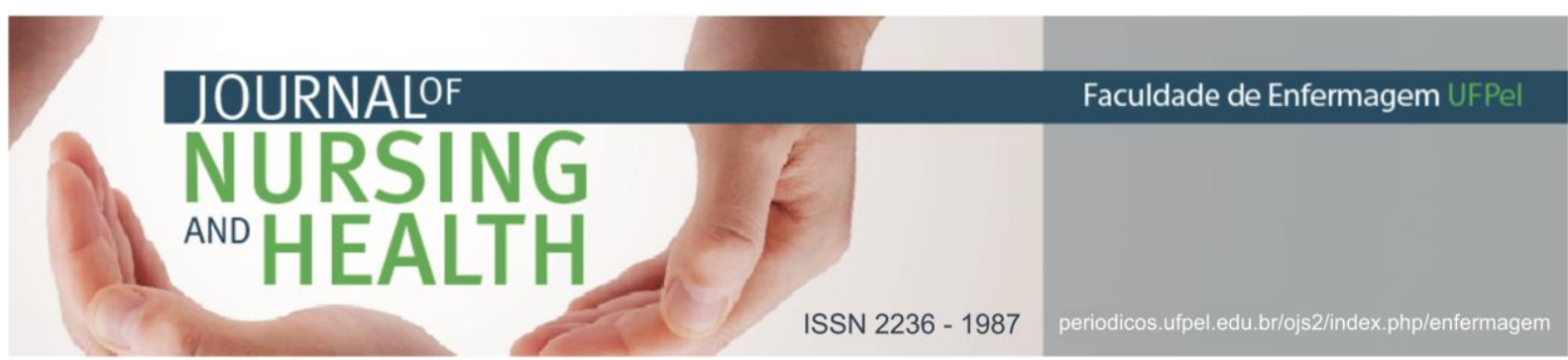

e não se esforçar para superar suas limitações, a situação vai permanecer a mesma, sem êxito!

Vale salientar que na década de 1980, quando o mundo estava no auge da busca pela melhoria da qualidade e da segurança dos serviços, estes mesmos pensamentos socráticos foram divulgados, pelo fundador de um dos mais importantes fabricantes de automóveis e motocicletas do mundo - a Honda. Ele colocou em prática as soluções de melhorias contínuas de cada trabalhador, implementando as suas reflexões por meio do método de gestão chamado método "Kaizen", o que significa "a transformação de si próprio". ${ }^{2}$

Diante disso, fez com que os trabalhadores apreendessem seus compromissos e responsabilidades. Ao colocar em ação a proposta para todos refletirem sobre a essência da vontade própria, de se transformar como pessoa consciente, de conhecer a sua própria fragilidade - assim, contribuindo para a superação de suas dificuldades e, ao mesmo tempo, favorecer a eliminação do conhecimento desnecessário, objetivando, padronizando e se apropriando de novos conhecimentos das ciências e da tecnologia. Esses elementos são extremamente necessários para o desenvolvimento das organizações e para o alcance dos objetivos individuais dos trabalhadores e da organização que fazem parte da sociedade como um todo.

Anteriormente, os resultados organizacionais eram considerados atributos da responsabilidade de uma organização isolada e de cada trabalhador individualmente. Mas, com as mudanças de perspectivas organizacionais, fomentaram-se novos entendimentos de que para alcançarmos objetivos individuais e institucionais, precisaríamos de esforços conjuntos de todos que se envolvem com a organização e com a sociedade.

Nesse sentido, podemos alertar que sem o entendimento necessário de que a pessoa que compõem e faz parte da organização, poderá muito bem refletir nos seus resultados finais da organização. Assim, observa-se a dimensão do valor de um produto que cada ser humano produz. Naturalmente, há necessidade contínua de efetivação do ciclo de controle/avaliação e retroalimentação em todo o contexto administrativo e organizacional, detectando o fenômeno que vem causando a degradação desnecessária, que compromete 0 valor da imagem social da organização.

Encerro a nossa reflexão sobre a temática deixando de lembrança as palavras simples, eternas e preciosas que a nossa precursora da Enfermagem, Florence Nightingale, deixou-nos. Observa-se que Florence tinha uma visão futurística e muito ampla do que seja a qualidade dos serviços de saúde e da segurança do paciente, como também, observa-se que, não é uma tarefa muito difícil de ser conquistada. Basta que cada um de nós pare, pensa e compreenda a profundidade dessas mensagens, em busca dos nossos sonhos de aproximar-se da qualidade e da segurança do paciente nos serviços de saúde, acompanhando sempre a evolução do tempo, sem esquecer-se dos princípios do ser humano que somos.

"A Enfermagem é uma arte; e para realizá-la como arte, requer uma devoção tão exclusiva, um preparo tão rigoroso, quanto à obra de qualquer pintor ou escultor..., é uma das ... a mais bela das artes do mundo! Escolhi os plantões, porque 


\section{JOURNALOF

sei que o escuro da noite amedronta os enfermos... na dor, no sofrimento, servir ao próximo porque sei que todos nós um dia precisamos de ajuda; Escolhi o branco porque quero transmitir paz; Escolhi estudar métodos de trabalho porque os livros são fontes de saber; Escolhi ser Enfermeira porque amo e respeito à vida!"... "Acho que os sentimentos se perdem nas palavras. Todos deveriam ser Transformados em ações, em ações que tragam resultados - Florence Nightingale. ${ }^{3}$

Descritores: Segurança do paciente; Cuidados de enfermagem; Enfermagem.

\section{REFERÊNCIAS}

1. Frases e Pensamentos de Sócrates. [acesso em 2017 set 26]. Disponível em: https://www.pensador.com/autor/socrates/biografia/

2. Kitaoka T. Gestão de Souichiro Honda. Tokyo: Kurashiki; 1992.

3. The edition of Notes on Nursing: A Guide for today's care givers is published by Elsevier in conjunction with the International Council of Nurses; 2009.

Publicação: 30/08/2017 